\title{
Microbial Carbon Sequestration - an IRCCM research project
}

\author{
Antje Boetius ${ }^{1,2,3}$ and Dieter Wolf-Gladrow ${ }^{1}$ \\ 1. Alfred-Wegener-Institute für Polar- und Meeresforschung, Columbusstraße, D-27568, \\ Bremerhaven
}

2. International University Bremen, P. O. Box 750561, D-28725, Bremen

3. Max-Planck-Institute for Marine Microbiology, Celsisusstr. 1, D-28359, Bremen

Biotic and abiotic processes, climate change, regional and global environmental issues, greenhouse gas emission, stratospheric ozone depletion, loss of biodiversity, desertification, freshwater availability, and air quality are all inter-linked. Understanding the driving forces and feedback mechanisms of these processes is essential for understanding the evolution and future of the earth, the environment, and society. It is important to realize that the ocean's carbon cycle plays an important role in the global element fluxes. In the following, we look at two major processes representing a sink for carbon in the ocean: 1) sedimentation of biogenic carbonate from productive surface waters, and 2) carbon sequestration by methane oxidation above gashydrate and other sites of methane seepage. We point out the necessity to monitor and understand the submarine environments at the interface between the geoand biosphere.

\section{What do we need to know about the ocean's carbon cycle?}

Key issues about the global carbon cycle and climate change:

- Which carbon reservoirs and which processes are responsible for the variation in $\mathrm{CO}_{2}$ on glacial/interglacial time scales?

- How does carbon sequestration function and which are the biological regulators determining how much carbon is removed from the atmosphere or kept in the ocean?

- How does the ocean, the land, and biota respond to natural variations (and anthropogenic perturbations)?

\section{1) THE BIOLOGICAL CARBON PUMP}

The ocean plays a major role in the global carbon cycle, exchanging $\mathrm{CO}_{2}$ with the overlying atmosphere. The uptake of atmospheric $\mathrm{CO}_{2}$ by the oceans is driven by physicochemical processes as well as biological fixation of inorganic carbon species. $98 \%$ of the atmosphere-ocean system carbon is stored in the ocean. The marine carbonate system is an essential component of the global carbon cycle. Due to the $\mathrm{CO}_{2}$ exchange at the air/sea interface, the oceans play an important role by regulating the amount of atmospheric carbon dioxide and are, thus, closely coupled to climate variability. Anthropogenic intervention alters the natural climate variability and raises the question of how environmental conditions might change in the future. To validate 


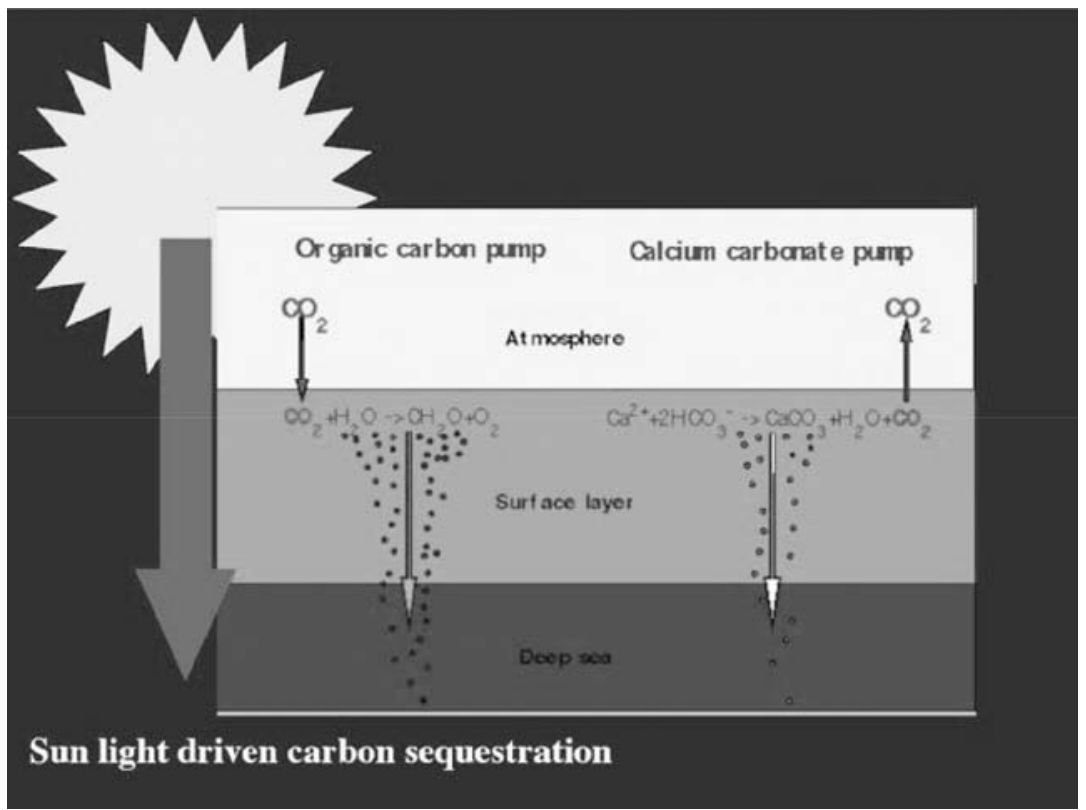

Figure 1

climate models, past climate reconstructions present the best opportunity. Useful information about the geological history of the marine carbonate system is preserved in ocean sediments. So-called "proxies" are used to reconstruct past ocean conditions. They are measurable descriptors that are closely correlated to desired, but unobservable, target parameters. For instance, the stable isotopic composition and trace element ratios within organic and inorganic compounds of microfossils are recorders for certain parameters describing the marine carbonate system such as temperature, alkalinity, and $\mathrm{pH}$. The biogenic production of organic material and carbonate minerals in the ocean's surface, and their subsequent transport to depth are termed the "biological carbon pumps." Two different biological carbon pumps can be distinguished. Photosynthetic carbon fixation and the flux of organic matter to depth, termed organic carbon pump, generates a $\mathrm{CO}_{2}$ sink in the ocean. In contrast, calcium carbonate production and its transport to depth, referred to as the carbonate pump, releases $\mathrm{CO}_{2}$ in the surface layer. These processes are driven by key micro-organisms in the sea, which have a global impact. Some of these key plankton species are available for detailed molecular, biochemical, physicochemical, and computational analysis in the lab.

\section{2) METHANE TURNOVER IN THE OCEAN}

Methane is one of the most important energy sources in the industrialized world, but is also an effective greenhouse gas when emitted into the atmosphere. Vast amounts of methane are formed in European margin sediments leading to the formation of free 


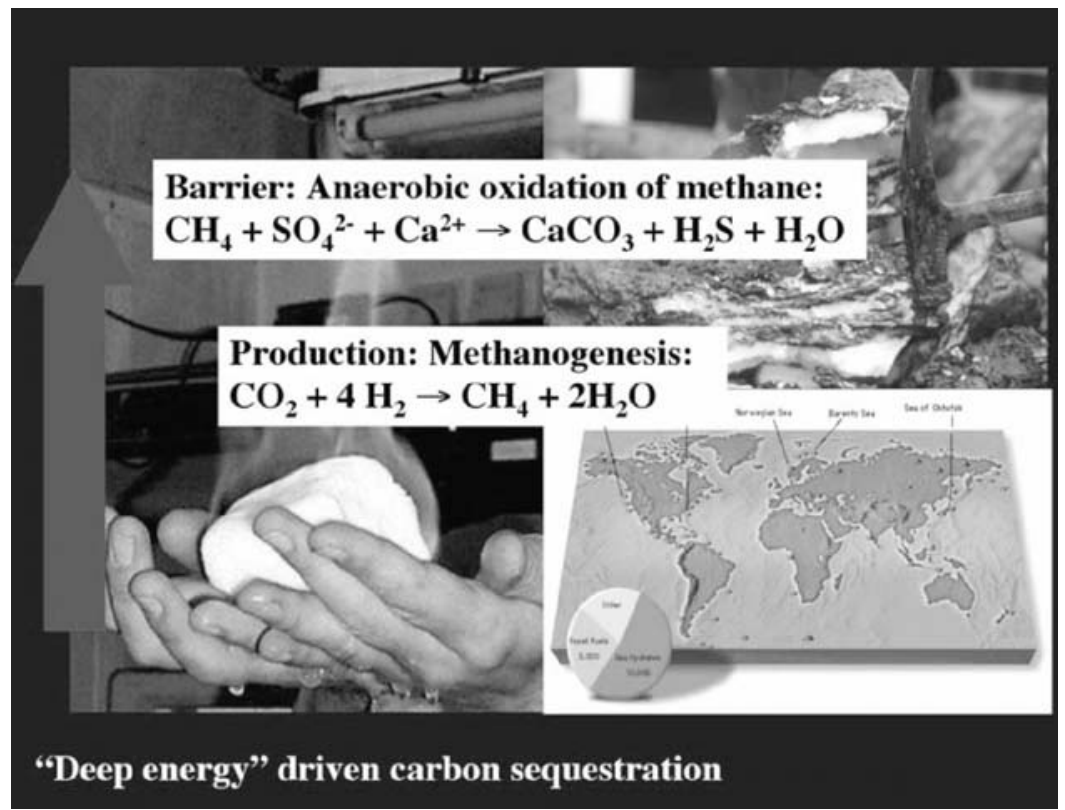

Figure 2

gas, to complex carbonate structures, and to enhanced methane emission. These processes are important for environmental quality, for offshore operations of the hydrocarbon industry, and for climate development. However, a high percentage of the entire methane flux, maybe $90 \%$, is retained in the seafloor through anaerobic oxidation by micro-organisms. However, continuous methane formation in margin sediments may lead to accumulations of free gas, to enhanced methane emission, and to complex carbonate structures. These consequences of marine methane cycling are important for environmental quality, for climate development, and for offshore operations of the hydrocarbon industry. Only recently the microbiological and geochemical controls of this methane barrier have been identified. It is essential to quantify current methane fluxes and to evaluate the effect of environmental change on sea floor methane release. High-quality data are needed on the processes responsible for the formation, accumulation, transport, and oxidation of methane in continental margin sediments. With this knowledge, we can develop analytical and predictive models on the complex processes determining methane fluxes in the sea floor and their regulation by environmental change. The goal of further projects on the methane cycle at continental margins is to understand the controls and mechanisms of methane production and breakdown in ocean margin sediments. Even at methane seeps and surficial gashydrates, an unknown - but probably major - part of the methane is biologically oxidized before it can escape into the water column. New data show that gashydrate reservoirs represent an enormous sink for carbon due to the high rates of microbial carbonate formation from methane turnover under anaerobic conditions. 


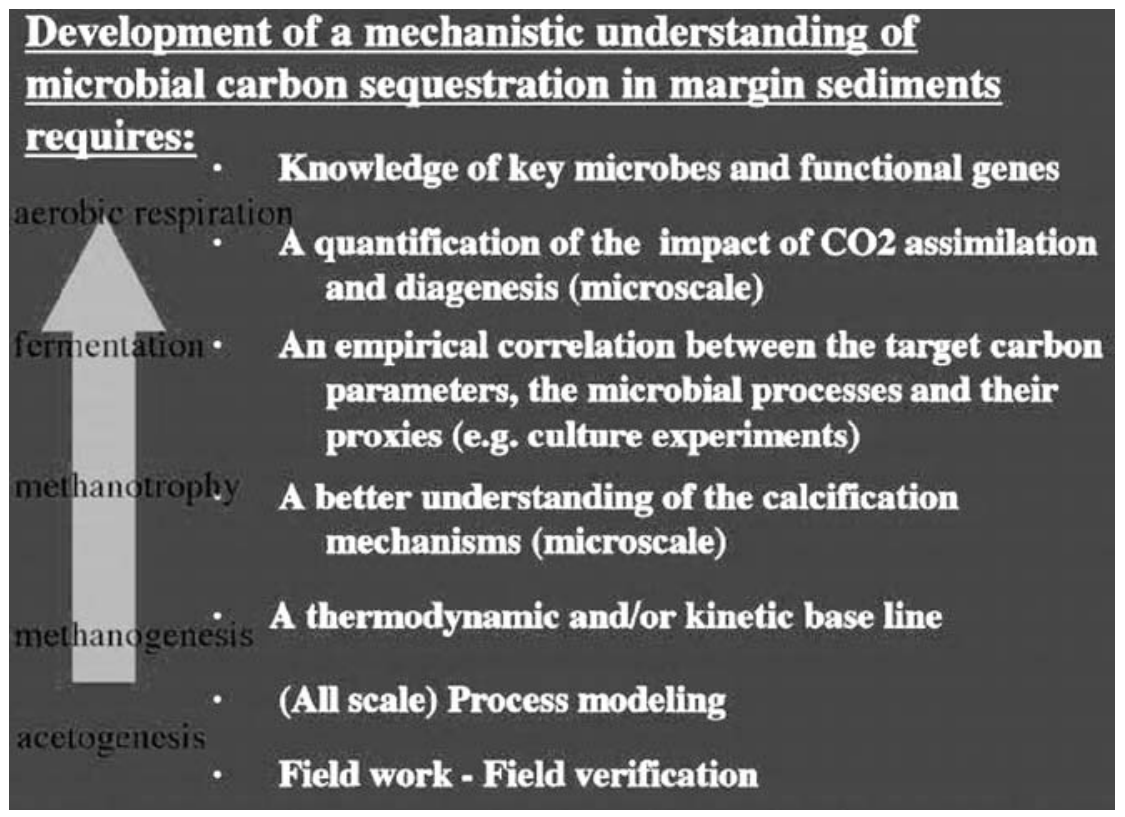

Figure 3

The key players, functioning, and the efficiency of this process must be understood if we are to quantify current methane fluxes in marine sediments and predict the effect of environmental change on sea floor methane release.

\section{3) CARBON CYCLING IN CONTINENTAL MARGIN ENVIRONMENTS - THE LINK BETWEEN SUBSURFACE AND SURFACE PROCESSES}

A number of fascinating ocean ecosystems such as cold water corals and sponge reefs, carbonate mounds, mud volcanoes, chemosynthetic seep communities, and cryptic microbial populations live deep beneath the seafloor. These deep ocean margin ecosystems have in common that they grow without sunlight at cold temperatures. A spectacular discovery has been the girdle of deep-sea reefs stretching along Europe's margins. The reefs are built by a variety of species like deep water corals, sponges, brittle stars, and sea lilies. These animals form rigid skeletons by calcium carbonate precipitation and they filter enormous amounts of water to collect food. Although growing very slowly, they build enormous and productive reefs, which shape the seafloor, provide shelter and food to a variety of other animals, act as nurseries for fish, represent a permanent sink for carbon and a cabinet for medicine and natural substances. Despite these many benefits, the reefs are already threatened by benthic fisheries, dredging, by petroleum exploration and drilling, by waste disposal and pollution. Another type of newly detected deep margin ecosystem comprises microbial communities and symbiotic animals, which are nourished by chemical energy rising from deep sources. At ocean margins, a variety of systems occur where subsurface 
fluids and gases are emitted into the ocean. Recently it was found that these fluid discharge zones have a strong influence on the distribution of biota on the seafloor and shape specific ecosystems fuelled by methane. A variety of dissolved and gaseous compounds can be emitted, such as methane, hydrocarbons, carbon dioxide, and hydrogen sulfide. These energy sources directly support chemosynthetic organisms and distinct biological communities. Hence, these fluid and gas seeps are highly dynamic sites where steep gradients of chemical energy link geosphere, biosphere, and hydrosphere. Currently, the global inventory of fluid seeps at passive continental margins is growing rapidly, but geological, chemical, and biological processes operating at those fluid seeps remain little known. Most interestingly, there appears to be a link between deep sources of fluid flow, microbial conversion of subsurface geochemical energy, and the formation of deep-water reefs and carbonate mounds, which has not been resolved.

An IRCCM project is envisioned which studies the pathways of microbial carbon sequestration. This project should investigate the major pathways of microbial carbon sequestration at different continental margin environments. Processes to be studied by field and laboratory work as well as by modelling include:

- microbial formation of methane deposited as gashydrate;

- microbial anaerobic oxidation of methane deposited as carbonate;

- microbial autotrophic fixation of $\mathrm{CO}_{2}$ deposited as organic substances and carbonate.

These processes play an important role in counterbalancing greenhouse gas emissions, but their functioning and regulation are not well understood. Central to this study will be the identification of key players, key enzymes, and key environmental conditions. 